\title{
O espaço liso e o diagrama aberto: a topologia poética de André Vallias
}

Yuri Kulisky

UFPR

\section{Resumo}

Segundo Roman Jakobson, a poesia estabelece sua qualidade diferencial por estar dotada de uma configuração (patterning) verbal subliminar - uma tessitura paralelística que ocasiona a justaposição de "figuras de gramática" e "figuras de som". Esta padronagem verbal daria uma espécie de "esqueleto abstrato" ao corpo do poema. Quando, na semiose, a metalinguagem implica-se como material integrante do signo, o ato criativo acaba por se confundir com ela - os paralelismos entre linguagem e metalinguagem passam a gerar figuras de figuras, o "esqueleto" vira do avesso e faz proliferar imagens ou diagramas de similaridade. Movimentos desta magnitude costumam originar saltos criativos; é a partir de um destes saltos que André Vallias inaugura um novo espaço de imaginação poética. Na seqüência de poemas desta fase (em especial Nous n'avons pas compris Descartes e de verso), o universo intervalado da textura alfabética e das distribuiçôes rítmicas ganha um ponto de contato com o universo contínuo das imagens: diagramas rítmicos, representantes in abstracto das oscilaçôes de intensidade entre as sílabas, tornam-se eles mesmos poemas. É tal captura crítica que, a partir dos conceitos de "espaço liso" e "diagrama aberto", intentamos analisar, pensando em como Vallias transforma a imaginação fonética da página numa imaginação topológica.

Palavras-chave: Poesia contemporânea; Poesia digital; André Vallias; Semiótica; Diagrama aberto.

\begin{abstract}
According to Roman Jakobson, poetry acquires its differential quality by being endowed with a subliminal verbal patterning - a parallelistic texturing that originates the juxtaposition of "grammar figures" and "sound figures". This verbal patterning inserts a kind of "abstract skeleton" into the body of the poem. When, in semiosis, metalanguage is implied as an integral material of the sign, the creative act ends up being confused with it - the parallels between language and metalanguage begin to generate figures of figures, the "skeleton" turns inside out in a proliferation of images or similarity diagrams. Movements of this magnitude usually give rise to creative leaps; it is by performing one of these leaps that André Vallias inaugurates a new space of poetic imagination. In the sequence of poems of this phase (in particular Nous niavons pas compris Descartes and de verso), the intervaled universe of discrete alphabetical structures and of rhythmic distributions touches the continuous universe of images: rhythmic diagrams, as abstract representations of the intensity oscillations between syllables, become themselves poems. It is such a metalinguistic approach that we try to understand. Departing from concepts such as "smooth space" and "open diagram", we try thinking about how Vallias translates the phonetic imagination of the page into a topological imagination.
\end{abstract}

Keywords: Contemporary poetry; Digital poetry; André Vallias; Semiotics; Open diagram. 
1 JAKOBSON, Roman.

Linguística. Poética. Cinema, 2004, p. 75.

\section{A padronagem verbal em poesia: gramática e geometria}

O linguista e teórico russo Roman Jakobson talvez tenha sido o primeiro a sistematizar o que ele mesmo chamou de "configuraçôes subliminares" em poesia. Com esta expressão, visava aquelas regularidades ocultas por sobre as quais o poema se constrói: as figuras sonoras da aliteração e da assonância, as figuras de sentido da comparação e da metáfora, as figuras sintáticas do paralelismo, etc. Segundo Jakobson, estes mecanismos parecem ser dotados de uma certa universalidade, e o poeta faz uso deles, mesmo que inconscientemente. Todos estes mecanismos apontam para outra afirmação fundamental do linguista: em poesia, a semelhança se superpóe à contiguidade. Cada uma dessas figuras póe em suspenso a concatenação puramente linear dos elementos gramaticais e cria afinidades eletivas entre elementos aparentemente desconexos, tudo a partir da semelhança. Assim, palavras sem nenhuma relação intrínseca podem se relacionar a partir da rima, da metáfora ou do paralelismo. Tais relaçôes podem ser conjuntivas ou disjuntivas, aproximando termos antinômicos ou reforçando o antagonismo de sentido entre termos. A poesia se definiria, portanto, como uma configuração (patterning) verbal que justapõe, de forma sintética ou antitética, "figuras de gramática" e "figuras de som", relacionando-as a partir de suas similaridades materiais. Este repertório de figuras, em parte já disponível na própria língua em que se escreve, em parte ainda por se fazer, é constantemente enfrentado quando alguém se propóe a manipular a matéria-prima verbal, seja para aceitá-lo, combinando-o de maneira exemplar, seja para renegá-lo, manipulando as próprias estruturas abstratas da língua em outras direçôes. A famosa distorção gerada pela poesia, na qual o eixo da semelhança (paradigma) se projeta sobre o eixo da contiguidade (sintagma) é uma espécie de intervenção deformante na geometria regular do plano cartesiano da língua.

Como consequência destes axiomas, a Jakobson ocorreu uma analogia bastante produtiva: a poesia mantém com a gramática uma relação semelhante àquela que a pintura mantém com a geometria: " $[\mathrm{H}]$ á uma analogia notável entre o papel da gramática na poesia e a composição pictórica baseada numa ordem geométrica latente ou manifesta e a que se baseia numa reação contra a disposição geométrica." ${ }^{1}$ A gramática adviria de uma capacidade abstrativa, da possibilidade de eliminar as determinantes concretas de um objeto linguístico (frase, palavra, morfema, fonema) em prol de uma estrutura dotada daquela "objetividade ideal" de que falava Husserl. A poesia, ao contrário, seria o terreno em que esta abstração toma corpo, em que a generalidade abstrata da gramática (re-)adquire seus contornos concretos. Como poesia, teria ainda sob si o repertório de operaçôes da gramática em 
suas determinantes abstratas; mas, na medida em que é capaz de torcer estas determinantes abstratas e as transformar em núcleos geradores de significado, é também capaz de aceitar as leis gramaticais na mesma medida em que as deturpa.

As operações do que se costuma chamar de "lírica moderna" foram uma agudizaçáo da revolta dos poetas contra a gramática. Talvez a chave disso esteja no fato de que, para muitos dos "poetas modernos", a gramática traçava uma espécie de limite do pensamento. Esta revolta se direcionou contra os pressupostos lógicos que, de modo bastante amplo, encamavam o pensamento ocidental: o princípio do terceiro excluído, a linearidade do significante, a primazia do verbo de cópula (ser), a divisão das classes gramaticais como correspondentes de determinadas categorias de pensamento (o substantivo e a substância, o adjetivo e o acidente, etc.). Para recuperarmos a analogia de Jakobson, é como se a poesia moderna desenvolvesse, no campo da linguagem, as geometrias não-euclidianas. É ainda num dos momentos poéticos da modernidade que o fator "geométrico" entrevisto pelo linguista russo torna-se ainda mais importante, com a entrada de um elemento que, de puro suporte, passa a ser parte fundamental da dinâmica semiótica do poema: o espaço da página. Se ele encontra já em Mallarmé uma função estrutural definida, outras correntes da poesia moderna como o futurismo, o dadaísmo, o cubo-futurismo russo e, no caso brasileiro, o concretismo, vão explorar facetas várias da dinâmica particular que o espaço da página adquire no poema. ${ }^{2}$

É a partir desta visada que podemos afirmar que certa fase da produção de André Vallias tem um intuito exploratório ou experimental na relação dinâmica entre a linguagem da poesia, suas formas variáveis de metalinguagem, e, em última instância, também seu suporte. Esta fase seria marcada por uma reflexão em torno das possibilidades tradutórias dentro da tríade apresentada acima (linguagem, metalinguagem, suporte). Em uma série que começa em 1991, com o poema Nous n'avons pas compris Descartes, o poeta explora ao máximo as potencialidades do espaço ortogonal em forma de grid, imbricando suas reflexões poéticas com a noção de diagrama aberto, conceito elaborado a partir de Charles S. Peirce, e a noção de imagem técnica, cunhada pelo filósofo tcheco Vilém Flusser. Esta série de poemas de Vallias radicaliza o processo de dinamização do espaço ao levar às últimas consequências a ideia de que a página não é apenas um suporte neutro; o poeta transforma, de um modo escritural-escultural, o próprio espaço em poema, adicionando uma camada suplementar de abstração concreta / concreção abstrata à complexa trama do verso e do ritmo.
2 A outra faceta que começa a ser explorada, de certo modo também a partir de Mallarmé, é a tipográfica. 
3 VALÉRY, Paul. Introdução ao método de Leonardo da Vinci, 1998, p. 24-25. Em verdade, a palavra "continuidade" incomodava um pouco o francês. $\mathrm{Na}$ marginalia do livro, ele anota: “[a] palavra continuidade não é de modo nenhum a ideal. Recordome de tê-la escrito em lugar de outra palavra que não encontrei. Eu queria dizer: entre coisas que não sabemos transpor ou traduzir para um sistema da totalidade de nossos atos. Isto é: o sistema de nossos poderes (pouvoirs)". A figura de pensamento que parece reger tal operaçáo é muito mais a figura do salto. Leonardo, esta personagem mental de Valéry, era capaz de saltar através do que, para nós, se apresenta como a mais radical descontinuidade. Talvez o que desgostasse Valéry na ideia de continuidade fosse o fato de que seu método não deveria continuar o descontínuo, colmar a lacuna, mas atravessar, traduzir, saltar através daquilo que parecia pura e simplesmente desconectado, ligar dois espaços cujas métricas são aparentemente incomensuráveis e mutuamente irredutíveis. $\mathrm{O}$ pensamento, quando apresentado a um limite, póe-se numa relação de contiguidade com o impossível. Se a impossibilidade é aquilo que o pensamento divide com seu próprio limite, o único modo de transpor este limite seria através da criação de um espaço intermediário, de uma ponte, que desarticularia a descontinuidade mesma deste espaço. O que o método esboçado por Valéry parece apontar é uma saída através da similaridade, o salto errático através do qual o limite é magicamente transformado, na qual ele não propriamente desaparece, e portanto mantém sua qualidade descontínua, mas a partir do qual é traduzido ou transladado através de sua relação com o "sistema dos nossos poderes”. No método Da Vinci-Valéry, o papel principal não é desempenhado pela mediação, mas pelo imediato.

4 Há um bom número de exemplos que Pignatari apresenta no capítulo "As decifraçóes semióticas", em Semiótica \& Literatura,

\section{O método Da Vinci-Valéry: um quiasmo de metalinguagens}

Façamos um desvio para estabelecer melhor a noção de metalinguagem. O francês Paul Valéry uma vez sonhou com um método que daria conta de uma espécie de analogismo universal entre o sensível e o inteligível, e que conferiria, por consequência, o estatuto de pensadores, no sentido mais radical do termo, aos artistas. Imaginava coroar o método com o nome de Leonardo da Vinci, para ele o exemplo mais bem-acabado de sua hipótese. $\mathrm{O}$ que o impressionava em Leonardo era o fato de que ele parecia ver relaçôes "entre coisas cuja lei de continuidade nos escapa". ${ }^{3}$ Esta capacidade abdutiva estava intimamente relacionada com uma outra visão da metalinguagem, de seu papel e de suas sutilezas. Não à toa Décio Pignatari chamou o método imaginado por Valéry de um "metamétodo". Cremos que, com isso, Pignatari aponta não para uma meta-metalinguagem, hierárquica e logicamente superior, mas para uma metalinguagem que atravessa sensivelmente seu próprio objeto, chegando ao ponto de ser indistinguível dele. Por vezes, o esforço criativo faz surgir esta metalinguagem que é interna ao próprio ato criativo - uma metalinguagem analógica -; a obra passa a ser seu próprio conteúdo, torna-se capaz de pensar a si mesma. Tal reabertura crítica, que revitaliza as regiốes entrópicas, é responsável pelos saltos ou picos criativos. ${ }^{4}$

Voltando a Jakobson, o resultado mais impactante da supremacia da similaridade sobre a contiguidade é que a metalinguagem da poesia não pode ser uma metalinguagem lógica: a imagem ideal da metalinguagem lógica é a de duas linhas paralelas: a cada ponto da linguagem-objeto corresponde um ponto da metalinguagem. Os pontos mantêm uma relaçáo biunívoca de equivalência ou identidade. Quanto à poesia, é preferível que sua metalinguagem funcione por assimilação, similaridade, abdução (que, além de ser uma categoria sígnica peirceana, é um sinônimo de rapto). É claro que nem toda a linguagem é porosa a uma primeira abordagem; os signos escapam de suas caixas toda vez que certa brutalidade da inteligência vem simplesmente predispô-las ao que elas já são (se a metalinguagem assimilasse completamente seu objeto, teríamos a máxima redundância, uma espécie de morte térmica da obra - e, de fato, aqui, temos de ser cuidadosos, a similaridade não está necessariamente ligada nem à identidade nem à equivalência). Há, para a inteligência flexível, um movimento de perseguição infinita na metalinguagem - um movimento gerador de informação, matricial, que faz com que toda a vez que cheguemos a um ponto de assimilação, o assimilado torne-se ainda uma outra coisa. A perseguição, portanto, se espirala.

Tal movimento pode ser exemplificado pelo que poderíamos chamar de regressâo ou descida ao suporte. Em seu livro Semiótica da arte e da arquitetura, Décio Pignatari empreende um interessante ensaio em redor do derradeiro quadro de Mondrian, o Victory Boogie-Woogie. Aqui, Mondrian é 
posto como o pintor da cidade, da metrópole. Em seu exílio em Nova York, teria visto a confirmação de suas teorias da época neo-plasticista. Décio trata a diagramação da tela como sendo uma espécie de figurativismo estrutural da cidade; um modelo das cidades possíveis (imagine-se uma fotografia aérea de uma cidade, por exemplo). Mas, neste mesmo Victory Boogie-Woogie, o holandês teria, segundo Pignatari, descido ao ritmo visual da própria tela:

A tela fala a sua própria linguagem, numa metamorfose meio incrível; a tela, aqui, não é metáfora: é um paramorfismo natural que virou paramorfismo artificial, ou seja, signagem. O suporte gera a ideia paramorficamente, numa relação isomórfica estrutura/super-estrutura. ${ }^{5}$

A metalinguagem torna-se interna ao ato criativo; a infralinguagem do próprio suporte subverte a supralinguagem de projeção estrutural; o tecido e a cidade se encontram. Num destes irônicos ricorsi viquianos, quando desce o trováo, os tempos convergem e os começos se coadunam aos começos.

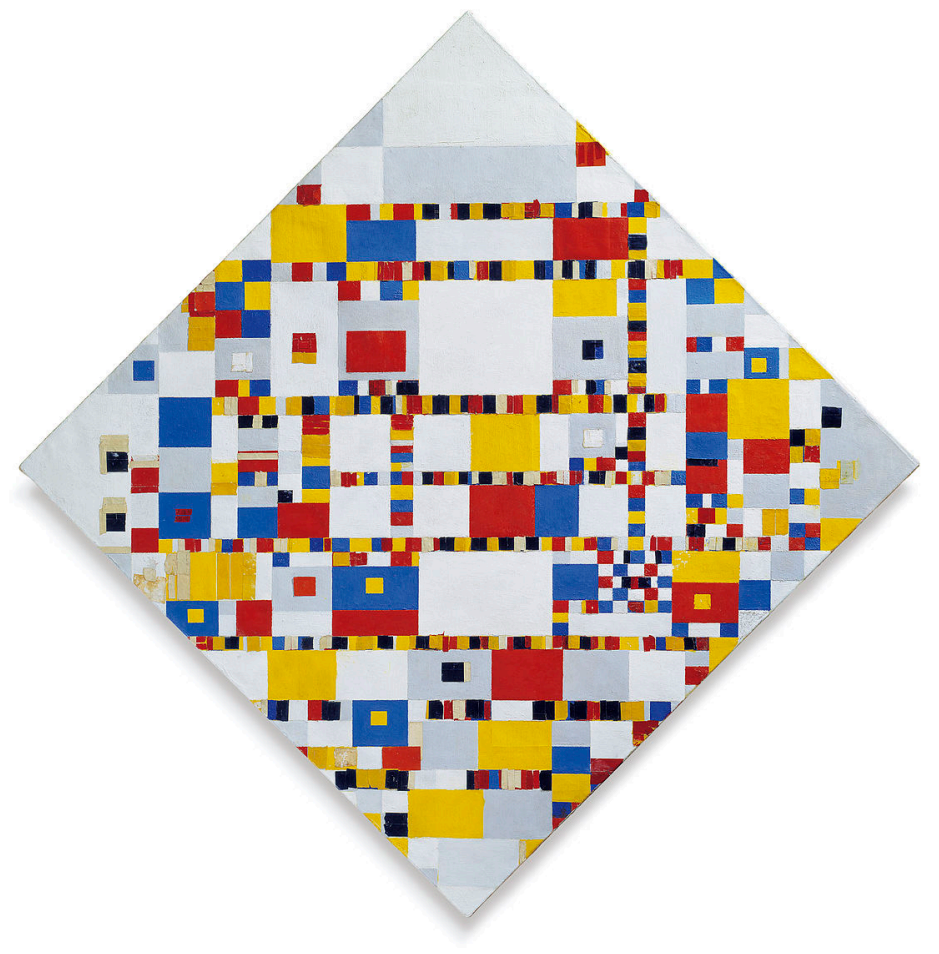

Figura 1: O Victory Boogie-Woogie, de Piet Mondrian

\section{Do espaço liso e do diagrama aberto}

Dado que os poemas de Vallias exploram uma translação do regime de intensidades do verso para um regime espacial de deformaçóes que é, ao mesmo tempo, um modelo metalinguístico da poesia alfabética e um objeto 
6 BOULEZ, Pierre. A música hoje, 2016, p. 84. poemático por si mesmo, é preciso estabelecer o modo a partir do qual este espaço captura determinadas qualidades da poesia alfabética e as reelabora. Os conceitos contrastivos de espaço liso e espaço estriado podem ser um ponto de partida para pensarmos as relaçóes entre o ritmo e as matrizes de visualidade que ele pode gerar. A oposição entre os dois conceitos surge pela primeira vez na obra do músico Pierre Boulez, quando, em um ensaio que discutia as bases do serialismo musical, ele aborda a relação entre os pulsos e os modos de ocupação dos espaços musicais (sejam eles definidos pelo ritmo, pela altura, pelo timbre, etc.):

O continuum se manifesta pela possibilidade de cortar o espaço segundo certas leis; a dialética entre contínuo e descontínuo passa, portanto, pela noção de corte; direi mesmo que o continuum é esta própria possibilidade; pois ele contém, ao mesmo tempo, o contínuo e o descontínuo: o corte, se o quisermos, muda o continuum de signo. [...] O espaço das freqüências pode sofrer duas espécies de cortes: uma, definida por um padrão, renovar-se-á regularmente; a outra, não precisa, não determinada, mais exatamente, intervirá livre e irregularmente. Para estimar um intervalo, o temperamento - escolha do padrão - será uma ajuda preciosa, ele "estriará" em suma, a superfície, o espaço sonoro, e dará à percepção [...] os meios de se orientar utilmente; no caso contrário, quando o corte for livre de se efetuar onde quiser, o ouvido perderá toda referência e todo conhecimento absoluto dos intervalos, comparável ao olho que deve estimar distâncias numa superfície idealmente lisa. A qualidade do corte define a qualidade microestrutural do espaço liso ou estriado, em relação à percepção; no limite, espaço estriado e espaço contínuo se fundem no percurso contínuo. ${ }^{6}$

A noção de um espaço que pode ser, alternadamente, ocupado por um padrão fixo, ou ocupado de modo livre, implica, portanto, uma relação de alternância. Se o "ritmo livre" ganha regularidade o suficiente (a partir da repetição, por exemplo), ele se direciona para o espaço estriado. Do mesmo modo, se a regularidade dos pulsos é introjetada por uma repentina complexidade, se começa um relacionamento irregular com outra série de pulsos, por exemplo, ela se direciona para o espaço estriado.

Esta alternância foi reaproveitada por Deleuze e Guattari no monumental Mil Platôs. Os autores operam uma espécie de aplicação múltipla do conceito, que passa a designar não só espaços musicais, mas a ser um qualificativo dos espaços em geral. Atribuem a noção de dimensional ao espaço liso e a noção de direcional ao espaço estriado:

[...] o estriado é o que entrecruza fixos e variáveis, ordena e faz sucederem-se formas distintas, organiza as linhas melódicas 
horizontais e os planos harmônicos verticais. O liso é a variação contínua, é o desenvolvimento contínuo da forma, a fusão da harmonia e da melodia em favor de um desprendimento de valores propriamente rítmicos, o puro traçado de uma diagonal através da vertical e da horizontal. ${ }^{7}$

Se voltarmos às proposições jakobsonianas, a oposição alternante entre o liso e o estriado nos parece uma visada interessante sobre a relação geométrico-estrutural entre gramática e poema. Tal oposição também estabelece vínculos com outras visadas sobre o espaço e sua relação com o ritmo. Elisabeth Walther-Bense, tratando do que Max Bense batizou de espaço semiótico, ${ }^{8}$ estabelece, para cada um dos três tipos básicos de signo na classificação peirceana (ícone, índice, símbolo) uma operação específica: o "ícone divide o espaço semiótico (o repertório) em dois âmbitos, por exemplo, em características coincidentes e características não coincidentes"; ${ }^{9}$ o índice une dois elementos; e o símbolo representa o espaço semiótico como repertório puro. Estas operaçôes básicas dos signos sobre o espaço-repertório também entram numa rede de alternâncias, a lei ou o padrão do símbolo (como modelo direcional) podendo retornar ao ícone (como modelo dimensional) e vice-versa. O conjunto de operaçóes acima exposto tem intuito analítico e metalinguístico, mas, nos parece, é a partir dele que André Vallias organiza algumas das matrizes de sua poética.

Poderíamos dizer, a partir do acima exposto, que o que a poética topológica de Vallias apresenta é uma espécie de operação icônica sobre o ritmo: ela divide o espaço através de coincidências e não-coincidências entre cheios e vazios. O ritmo foi definido por Pignatari como "um ícone que resulta da divisão e distribuição no tempo e no espaço - ou do tempo e do espaço - de elementos ou eventos verbivocovisuais (= verbais, vocais, visuais)." ${ }^{10}$ Estes eventos, dados ao leitor como livre manipulação combinatória, se alternam ou distribuem num espaço passível de deformação, de modelagem, e a partir do qual se desenha um grande diagrama ${ }^{11}$ das relaçóes rítmico-visuais relacionadas ao espaço do verso.

O diagrama aberto de Vallias é um modus a partir do qual um diagrama se abre para outras linguagens; a partir do qual, em suma, o poema, entendido como um diagrama de suas qualidades materiais, adquire certa porosidade em relação aos materiais advindos dos códigos mais heterogêneos:

O conceito de poema como diagrama aberto, ao incorporar as noçôes de pluralidade, interrelação e reciprocidade de códigos, não só garante a viabilidade da poesia numa sociedade sujeita a constantes revoluçóes tecnológicas, como lhe confere uma posição privilegiada $\rightarrow$ a de uma poesia universal progressiva (como antevia Schlegel) ou simplesmente: poiesis (do grego = criaçáo, feitura). ${ }^{12}$
7 DELEUZE, Gilles;

GUATTARI, Félix. Mil Platôs, v. 5, 2012, p. 197.

8 WALTHER-BENSE, Elisabeth. A Teoria geral dos signos, 2010, p. 69.

9 Idem. p. 47.

10 PIGNATARI, Décio. O que é comunicação poética, 2011, p. 21.

11 "A diagram is commonly understood as a drawing conveying information about something incorporeal. From the Greek diagramma, it means to mark out by lines, to draw - where dia is through, across, apart and graphein is to write. The diagram is defined as a geometrical figure used to illustrate theorems. It can also be a sketch, a drawing or a plan that explains a thing by outlining its parts and their relationships - basically, delineating its inner workings. Finally, a diagram can be defined as a chart or a graph explaining or illustrating ideas and displaying statistics. A diagram can be seen in the form of three different types of drawings: a plan, a map and a graph (or a schema). A plan represents a building that is not yet built. A map represents terrains on which we have not yet travelled. A graph displays relations between variable quantities. No matter what form it takes as a representation, a diagram is a configuration of lines, whether they are drawn or written". (ZDEBIK, Jakub. Deleuze and the diagram: Aesthetic Threads in Visual Organization, 2012, p.1.)

12 VALLIAS, André. De verso. Disponível em: http://www.andrevallias.com/deverso/deverso.htm. Acesso em: 9 nov. 2017. 
Portanto, a geometria poética proposta por Vallias é o resultado de uma operação metalinguística (ou, para recuperar um termo de Pignatari, metasígnica) que isola o componente alfabético da poesia para transformá-la em intensidade sonora e rítmica desligada do alfabeto, ou que apenas pressupóe o alfabeto de modo latente, extraindo o componente de intensidade e manipulando-o livremente.

Esta operação é usada de modo diverso, porém complementar, em dois dos poemas mais emblemáticos desta fase.

\section{Nous n'avons pas compris Descartes}

O recurso explorado no poema Nous n'avons pas compris Descartes é o da contraposição de uma superfície ortogonal lisa, que ele chama de página (page), e uma superfície dotada de uma dupla curvatura, que ele chama de poema (poem).

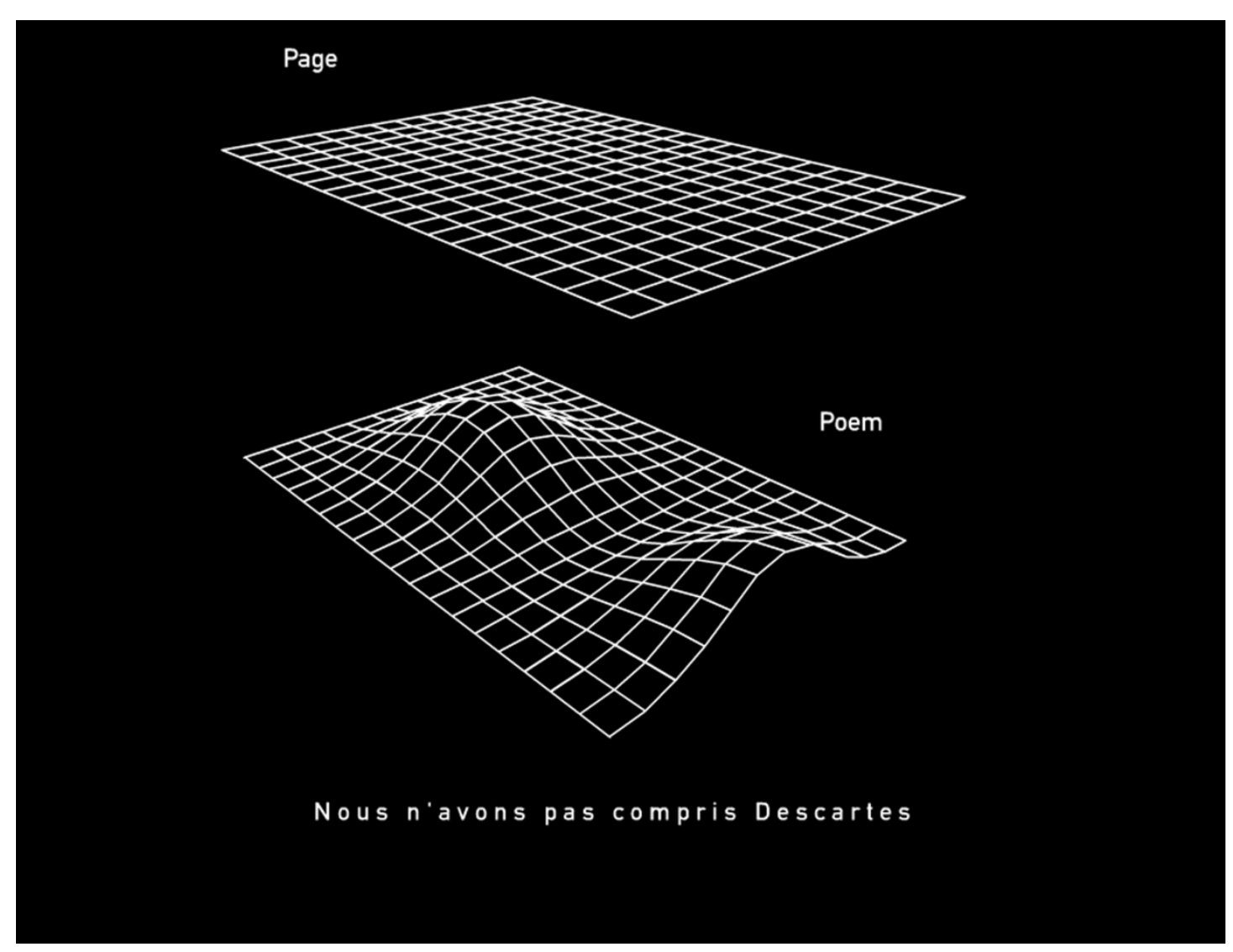

Figura 2: captura de tela do poema Nous n'avons pas compris Descartes.

De agente estrutural que interagia com a disposição alfabético-tipográfica do poema, o espaço da página passa a ser ele mesmo um objeto poemático. Tal solução inaugura um novo espaço de imaginação, que eu gostaria de chamar topológico, pois as similaridades distributivas entre acentos (que são 
a base do verso) e as similaridades sonoras entre fonemas (que se alinhavam na paronomásia) se traduzem numa atração entre espaços: a força centrípeta do poema, que deformava a axialização cartesiana entre o contíguo e o similar, faz o espaço da página se dobrar em poema. Ela indicia, pela dobra, a matéria sensível insurgente. Para citar Roland Azeredo Campos:

[...] o espaço achatado é pressuposto da geometria de EuclidesDescartes, mas caracteriza igualmente a de Minkowski, arcabouço da relatividade restrita de Einstein. O espaço-tempo curvo se associa à outra relatividade, a geral, teoria de gravitação que prevê o arqueamento nas proximidades da matéria, sendo tão mais intenso quanto maior for a densidade. $\mathrm{O}$ cogito cartesiano assevera o salto do pensamento abstrato à existência. Do substrato mental ao material. Vallias propóe também um salto: da planura deserta da página para o planar recurvo que desenha a materialidade do poema. Este existe porque existe a página, a tela do computador, a mente. A curvatura, expressão gráfica do signo criativo, é forma-conteúdo, é matéria-energia, tal como na gravitação einsteiniana. A folha quadriculada e lisa magicamente se transmuda num tapete voador ondeante. Efeito da in(ter)venção humana, conseqüência da vida. $\mathrm{O}$ artista pensa. Ergo, existe a arte. ${ }^{13}$

Seguindo a cascata de atos metalinguisticos que constituem as operaçôes poéticas de Vallias, este mesmo poema também pode ser lido como um aforismo visual: o nome de Descartes é imediatamente associado ao cogito. Esta seria, para muitos, sua contribuição máxima à filosofia. Vallias, seguindo Mallarmé, parece discordar de tal afirmação. Ele vê a maior contribuição de Descartes como sendo a invenção da geometria analítica, a partir da qual dois grandes campos da matemática, antes incomunicáveis, passam a comentar reciprocamente um ao outro: a álgebra passa a poder ser expressa geometricamente e vice-versa. Esta conquista cartesiana poderia ser uma das ilustrações ao método valéryano, e guarda um interessante isomorfismo com o empreendimento de Vallias: se na geometria analítica o reino discreto dos números é traduzido no reino contínuo do plano, na poesia topológica de Vallias, o reino discreto dos sinais alfabéticos é transposto em desenhos de intensidades rítmicas. ${ }^{14}$

\section{De verso: contraduçóes espaciais}

No poema de verso, o espaço topológico re-diagrama os ritmos de paralelismo num continuum novo, num salto que, indo para a poesia computacional, arrasta consigo as potencialidades, agora renovadas, do texto, da textura no espaço da página - aqui se dá um encontro intempestivo entre
13 VALLIAS, André. Disponível em: http://www.andrevallias.com/ textos/txt01.htm. Acesso em: 09 mar. 2017.

14 Em outros projetos, como Oratorio ou Trakltakt, poemas de corte mais "tradicional" são acompanhados de sua tradução topológica. Os acentos são marcados como aclives e as sílabas não acentuadas como declives. Esta tradução topológica adquire, a depender da moldura, outros significados possíveis: em Oratorio, por exemplo, ela faz remissão ao relevo acidentado da cidade do Rio de Janeiro. 
15 PIGNATARI, Décio. Semiótica da arte e da arquitetura, 2009, p. 115-116. técnicas arcaicas (a escrita bustrofédica e a metáfora da página como um campo) e técnicas pós-Segunda Revolução Industrial (o computador e a organização em grids, as modelagens tridimensionais). A página é, portanto, a espiral do encontro, o avanço-recuo simultâneo que leva ao salto. Como em Mondrian, a obra é levada a lembrar-se de seu suporte último, de seu apoio numa espécie de rede alfabética (agora ressignificada). Pignatari, ao pensar o fenômeno da escritura, escreve o seguinte:

quando um ícone visual se organiza com base numa estrutura que permite sua repetição e suas variaçóes, ele tende a gerar escritura. Quando a escritura reverte à unicidade visual, pela pura visão icônica de suas formas, transforma-se em ícone único com a possibilidade e a qualidade de um primeiro. ${ }^{15}$

A descoberta de Vallias parece ser a de uma escritura do ritmo, uma espécie de escultura-escritura visual que é pura ritmação, jogo de semelhanças e dessemelhanças, de sínteses e disjunções. Mas também um arar-se do ritmo, a inscrição do ritmo no espaço e no campo: um avolumar-se do ritmo.

O modo de "funcionamento" ou manipulação interativa do poema se dá da seguinte forma. O leitor é apresentado a um espaço ortogonal liso:

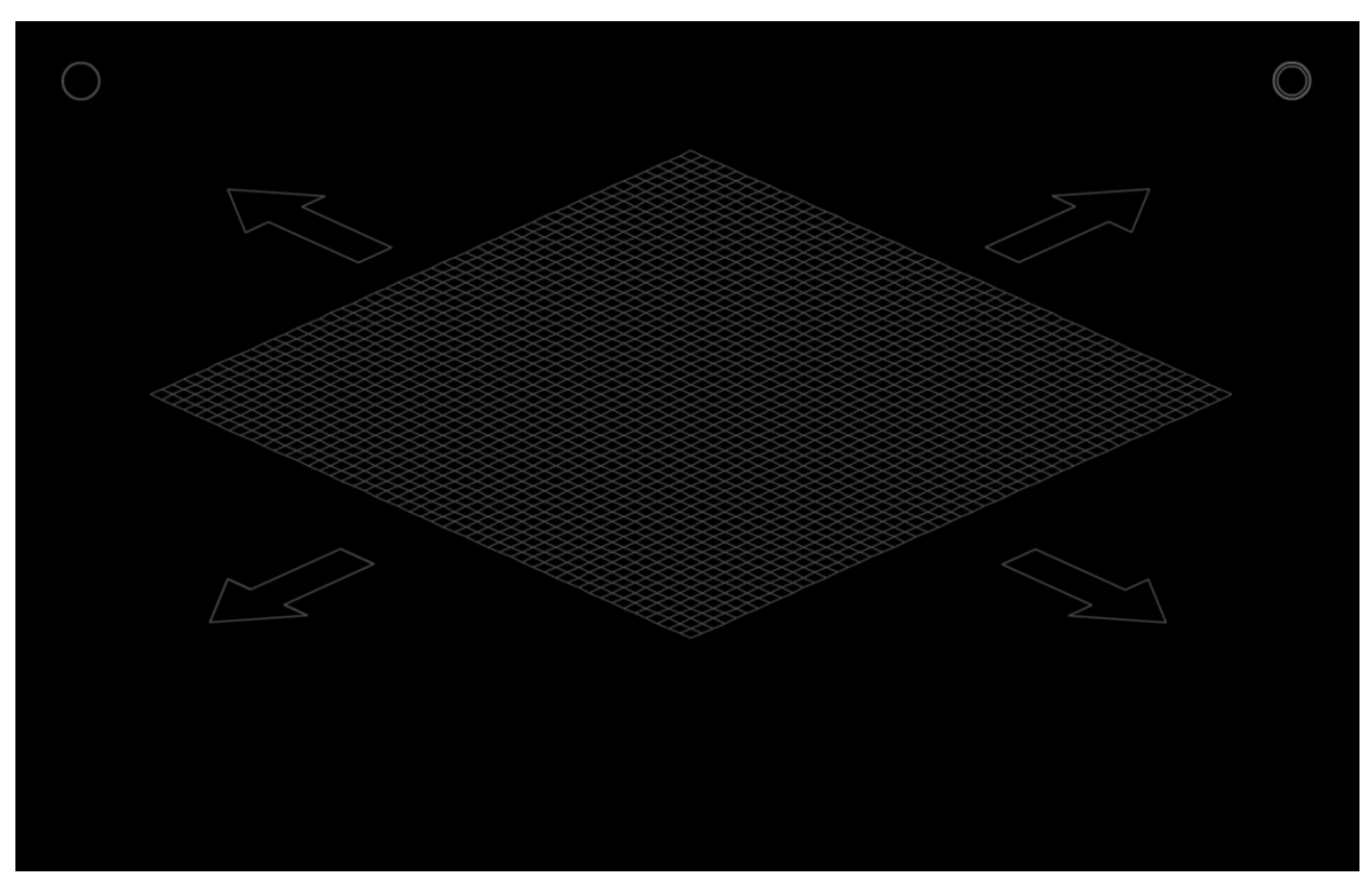

Figura 3: Captura de tela do poema de verso.

Cada uma das coordenadas (flechas) representa um tipo de pé métrico, que deforma o campo num ritmo correspondente ao seu padrão (as longas são transformadas em planos e as curtas em vales). Os formantes do plano 
são, portanto, os quatro pés métricos básicos da versificação greco-latina, que se opóem em duplas: o iambo (sílaba átona e sílaba tônica, relacionado ao ato de lançar) se opóe simetricamente ao troqueu (sílaba tônica e sílaba átona, relacionado ao ato de correr), enquanto o anapesto (duas átonas seguidas de uma tônica, relacionado ao ato de rebater) se opóe ao dáctilo (uma tônica seguida de duas átonas, relacionado à figura do dedo). Há ainda as ligaçôes laterais entre o troqueu e o dáctilo (um dáctilo interpretado como um troqueu seguido de uma átona) e o iambo e o anapesto (um anapesto interpretado como uma átona seguida de um iambo). O leitor pode estabelecer quais metros/deformaçóes interagem para criar padróes diferentes no plano.

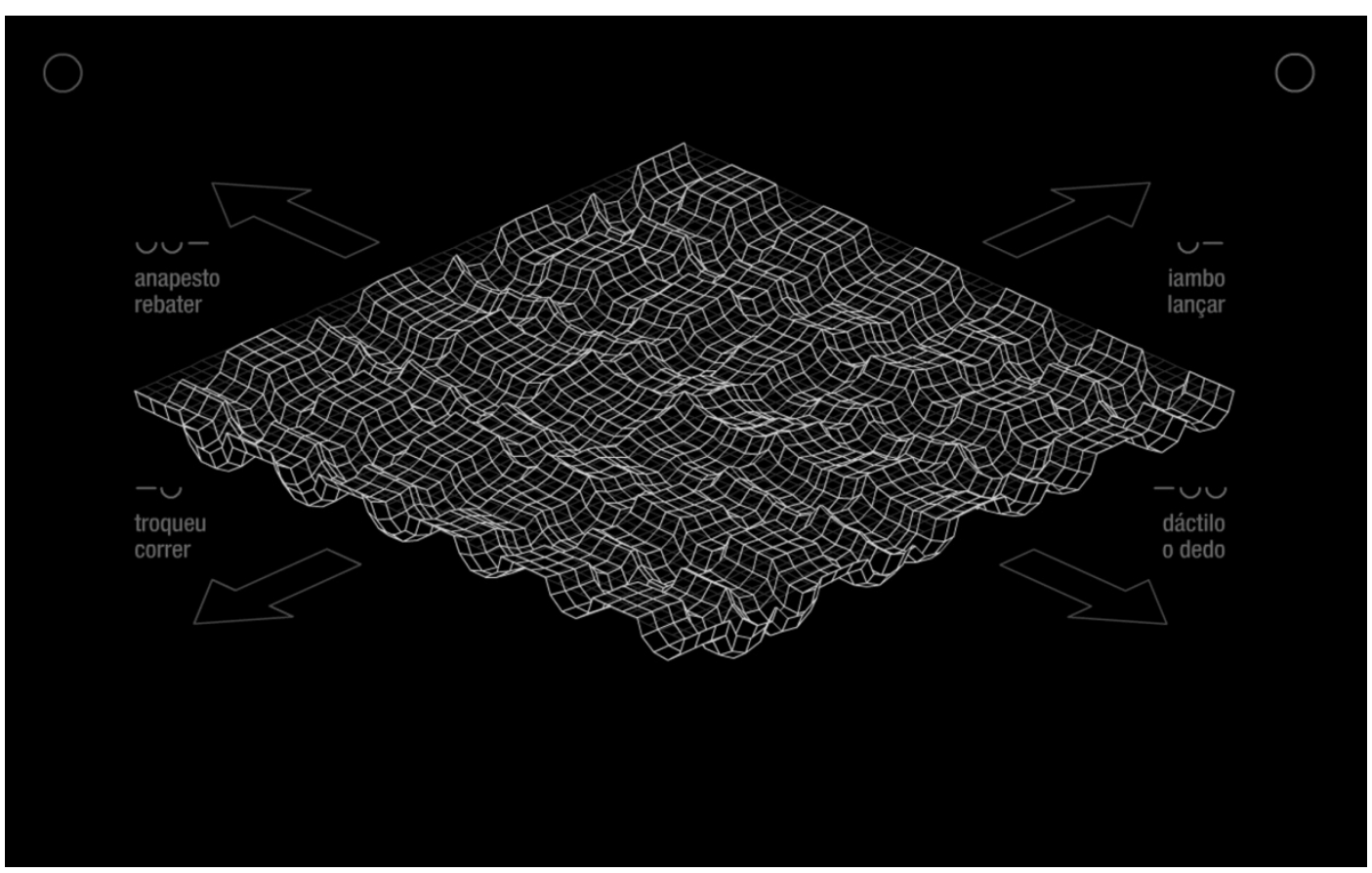

Figura 4: Captura de tela do poema de verso, com todos os vetores (pés métricos) acionados.

Falando sobre a inteligência brasileira, Max Bense disse que "[c]artesiana é a legitimação de uma coisa por meio da indicação do método de sua criação." ${ }^{16}$ A remissão a Descartes em um dos poemas torna-se ainda menos trivial. A exposição ideográfica do método de transformação da página em poema, através da curvatura, é uma exposição do modo de construção do próprio poema: ele apresenta, ao mesmo tempo, uma proposição geral sobre a poesia e seu método de efetuação como poema. Em de verso, a página, como espaço da criação rítmica, expóe cartesianamente o método de sua deformação.

A distribuição específica que Vallias empreende em de verso é também uma tradução do audível em visível, e do visível em computável: para definir o padrão de deformação espacial sofrida pelo plano, Vallias apela para 
17 Esta trama bastante complexa de códigos pode ser entendida como um cruzamento de vários sistemas de "de-cifração", como entendidos por Flusser: "Não é necessário conhecer instruçóes de quantidade para saber que as cifras são recipientes vazios que devem selecionar quantidades de alguma coisa" (em $A$ escrita, 2010 , p. 133-137). Se o sistema silábico seleciona uma intensidade sonora, o plano de Vallias pode ser lido como uma cifraçáo-decifração visual do sistema silábico. a tradução visual do ritmo de cada pé métrico ("U” = sílaba átona / breve e “-” = sílaba tônica / longa, assim, o troqueu seria traduzido por “-U”, o iambo por "U-", etc.). Ele estabelece, no plano, o "vazio" visual dos declives e o "cheio" visual dos planos como princípios de tradução da codificação rítmica, que "seleciona" uma determinada quantidade sonora (no caso, as duas seleçôes possíveis são a sílaba tônica e a sílaba átona). A binariedade desses dois princípios construtivos faz remeter à codificaçáo binária do computador $\left(1=\right.$ sílaba tônica, 0 = sílaba átona). ${ }^{17}$ Esta rede de transformaçôes contínua, esta capacidade de saltar entre códigos os mais diversos, de criar na página um espaço centrípeto a partir do qual uma multiplicidade de códigos pode coexistir, apontando-se mutuamente, é o que dá aos poemas de Vallias seu interesse fundamental.

\section{Referências}

AZEREDO CAMPOS, Roland de. Sobre "Nous n'avons pas compris Descartes". Disponível em: http://www.andrevallias.com/textos/txt01.htm. Acesso em: 9. nov 2017.

BENSE, Max. Pequena Estética. 2. ed. Tradução de Haroldo de Campos. São Paulo: Perspectiva, 1975.

BOULEZ, Pierre. A música hoje. 3. ed. Tradução de Reginaldo de Carvalho e Mary Amazonas Leite de Barros. São Paulo: Perspectiva, 2016.

BOULEZ, Pierre. Inteligência Brasileira. Tradução de Tércio Redondo. São Paulo: Cosac Naify, 2009.

DELEUZE, Gilles; GUATTARI, Félix. Mil Platôs. v. 5, 2. ed. Tradução de Ana Lúcia de Oliveira e Lúcia Cláudia Leão. São Paulo: Editora 34, 2012.

FLUSSER, Vilém. A escrita. Tradução de Murilo Jardelino da Costa. São Paulo: Anna Blume, 2010.

FLUSSER, Vilém. Filosofia da caixa preta: ensaios para uma futura filosofia da fotografia. Rio de Janeiro: Relume Dumará, 2002.

JAKOBSON, Roman. Linguistica. Poética. Cinema. Tradução de Tradução Haroldo de Campos. 2. ed. São Paulo: Perspectiva, 2004.

JAKOBSON, Roman. Poética em ação. Tradução de João Alexandre Barbosa. São Paulo: Perspectiva, 1990.

PEIRCE, Charles Sanders. Semiótica. Tradução de Jose Teixeira Coelho Neto. São 
Paulo: Perspectiva, 2010.

PIGNATARI, Décio. O que é comunicação poética. 10. ed. São Paulo: Ateliê Editorial, 2011.

PIGNATARI, Décio. Semiótica da arte e da arquitetura. 4. ed. São Paulo: Ateliê Editorial, 2009.

PIGNATARI, Décio. Semiótica \& Literatura. São Paulo: Ateliê Editorial, 2004.

VALÉRY, Paul. Introdução ao método de Leonardo da Vinci. Tradução de Geraldo Gerson de Souza. São Paulo: Editora 34, 1998.

VALÉRY, Paul. Variedades. Tradução de Maiza Martins de Siqueira. São Paulo: Iluminuras, 2007.

VALLIAS, André. De verso. Disponível em: http://www.andrevallias.com/deverso/ deverso.htm. Acesso em: 9 nov. 2017.

VALLIAS, André. Nous n'avons pas compris Descartes. Disponível em: http://www. andrevallias.com/poemas/nous.htm. Acesso em: 9 nov. 2017.

VALLIAS, André. Oratorio. Disponível em: http://www.andrevallias.com/oratorio/. Acesso em: 9 nov. 2017.

VALLIAS, André. Trakltakt. Disponível em: http://www.andrevallias.com/trakltakt/. Acesso em: 9 nov. 2017.

WALTHER-BENSE, Elisabeth. A Teoria geral dos signos. Tradução de Perola de Carvalho. São Paulo: Perspectiva, 2010.

ZDEBIK, Jakub. Deleuze and the diagram: Aesthetic Threads in Visual Organization. London: Continuum, 2012. 